study of the effects of bereavement on physical and mental health.

Although the study was based on a single practice several recommendations can be made. Poor communication may be due to a variety of reasons, but one main cause can be attributed to the large number of people who may be involved in the terminal care. Members of a multidisciplinary team must know each other's roles and must be able to develop strategies to allow them to work together.

A second recommendation is to advise relatives about the services available and to encourage them to use them. ${ }^{6}$ Practices could produce leaflets on the services and aids available locally. These leaflets could also list the other members of the primary health care team, explaining their roles and outlining how they could help patients and their relatives. Many charities already produce leaflets to help patients and relatives find help and enable them to cope with their illnesses and the common problems encountered.

Thirdly, there is a need for improvement in the organisation of bereavement counselling, particularly home visits initiated by the general practitioner. We recommend that general practitioners undertake bereavement counselling and that there is a well organised system for following up bereaved relatives.
Perhaps practices could keep diaries and systematically plan post-bereavement visiting in the following year. It is also important to record deaths in a relative's case notes. Many relatives present at the surgery around the anniversary of a loved one's death, and unless the doctor is aware of this the real reason for the consultation - for example, a depressive illness - can be missed.

Finally, as bereavement commonly causes an increase in both psychiatric and non-psychiatric symptoms ${ }^{7}$ it is important that general practitioners not only are aware of this fact but also that they know how to deal with it.

I thank the general practitioners and relatives of the deceased for participating in this study, and Mrs A Moss and Mrs H Smith for secretarial help.

1 Haines A, Booroff A. Terminal care at home. Br Med f 1986;292:1051-3. 2 Cartwright A, Hockey L, Anderson JL. Life before death. London: Routledge, 1973.

3 Doyle D. Domiciliary terminal care. Edinburgh: Churchill Livingstone, 1987:

Wilkes E. Dying now. Lancet 1984;: i:950-2.

5 Palmer KT. Notes for the MRCGP. Oxford: Blackwell Scientific, 1988:113.

6 Reilly PM. Patten MP. Terminal care in the home, $7 \mathrm{R}$ Coll Gen Prat 1981:31:531-7.

7 Parkes CM. Effects of bereavement on physical and mental health-a study of the medical records of widows. Br Med f 1964;ii:274-9.

(Accepted 29 December 1989)

\title{
Effect of reactive pharmacy intervention on quality of hospital prescribing
}

\author{
C J Hawkey, S Hodgson, A Norman, T K Daneshmend, S T Garner
}

University Hospital, Nottingham NG7 2UH C J Hawkey, DM, reader, department of therapeutics S Hodgson, BPHARM, senior pharmacist, pharmacy department

$\mathrm{T} \mathrm{K}$ Daneshmend, $\mathrm{MD}$, lecturer, department of therapeutics

S T Garner, BSC, district pharmaceutical officer, pharmacy department

Nottingham City Hospital, Nottingham NG5 1PB

A Norman, BPHARM, project manager

Correspondence to: Dr Hawkey.

Br.Med f 1990;300:986-90

\section{Abstract}

Objective-To evaluate the medical impact of reactive pharmacy intervention.

Design-Analysis of all interventions during 28 days by all 35 pharmacists in hospitals in Nottingham.

Setting-All (six) hospitals in the Nottingham health authority (a teaching district), representing 2530 mainly acute beds, 781 mental illness beds, and 633 mainly health care of the elderly beds.

Patients-Hospital inpatients and outpatients.

Interventions-Recording of every important intervention made by pharmacists to prescriptions for both inpatients and outpatients when they perceived inadequacies of drug prescription or administration, including characterisation of the problem, coding of outcome, recording of time taken to initiate and resolve intervention, and grade of prescribing doctor. The problems were independently assessed for their potential to cause medical harm.

Results-769 Interventions (about $2.9 \%$ of prescriptions) were made, of which 60 concerned prescriptions rated as having a major potential for medical harm. The commonest problems concerned dosage, which was wrong in 280 prescriptions (102 for antibiotics) and not stated in 50 (one for antibiotics), especially those associated with a major potential for medical harm ( 32 prescriptions). These concerned sedatives; analgesics; cardiovascular drugs or diuretics; and iron, vitamin, or mineral preparations. Also common were overprolonged prescription of antibiotics (48 prescriptions), confusion of drug names (nine), and inadvertent coprescription of excessive quantities of aspirin or paracetamol in plain and compound preparations (seven). The pharmacist's recommendation was accepted in 639 instances (86\%), and the prescription was altered in 575 , leading to an appreciable (246 cases) or minor (231 cases) improvement. Interventions had little effect on costs; 427/646 had no effect and 130 produced savings $<50 \mathrm{p}$. Pharmacy intervention $(730 / 769$ interventions) occupied on average 41 minutes per pharmacist per week.

Conclusions-Most reactive pharmacy interventions concerned prescribing errors with a limited potential for medical harm, but a small number of detected errors with a major potential for medical harm; cost savings were not appreciable.

\section{Introduction}

The quality of hospital prescribing in the United Kingdom could be improved. The inappropriate use of drugs represents a potential hazard to patients and an unnecessary expense. It has been suggested that greater involvement of pharmacists in the treatment of patients might lessen hazards and reduce costs, ' and recently pharmacists have been increasingly concerned in ward rounds, ${ }^{1-3}$ case conferences, ${ }^{4}$ information services, ${ }^{5-7}$ and dosage advice services based on therapeutic drug monitoring. ${ }^{89}$

Intervention by pharmacists in prescribing by doctors has taken several forms. Active campaigns by pharmacists have sought to alter prescribing in specific areas. The use of guidelines, particularly when backed up by personal visits, reduces the inappropriate use of antibiotics (notably cephalosporins), ${ }^{10-14}$ parenteral nutrition, ${ }^{15}$ albumin, ${ }^{16}$ dextropropoxyphene, ${ }^{14} 17$ cerebral and peripheral vasodilators, ${ }^{14}$ and diazepam, ${ }^{18}$ although the effects of such targeted interventions may be transient. ${ }^{19}$ Pharmacists have also contributed to establishing drug information services, and there is 


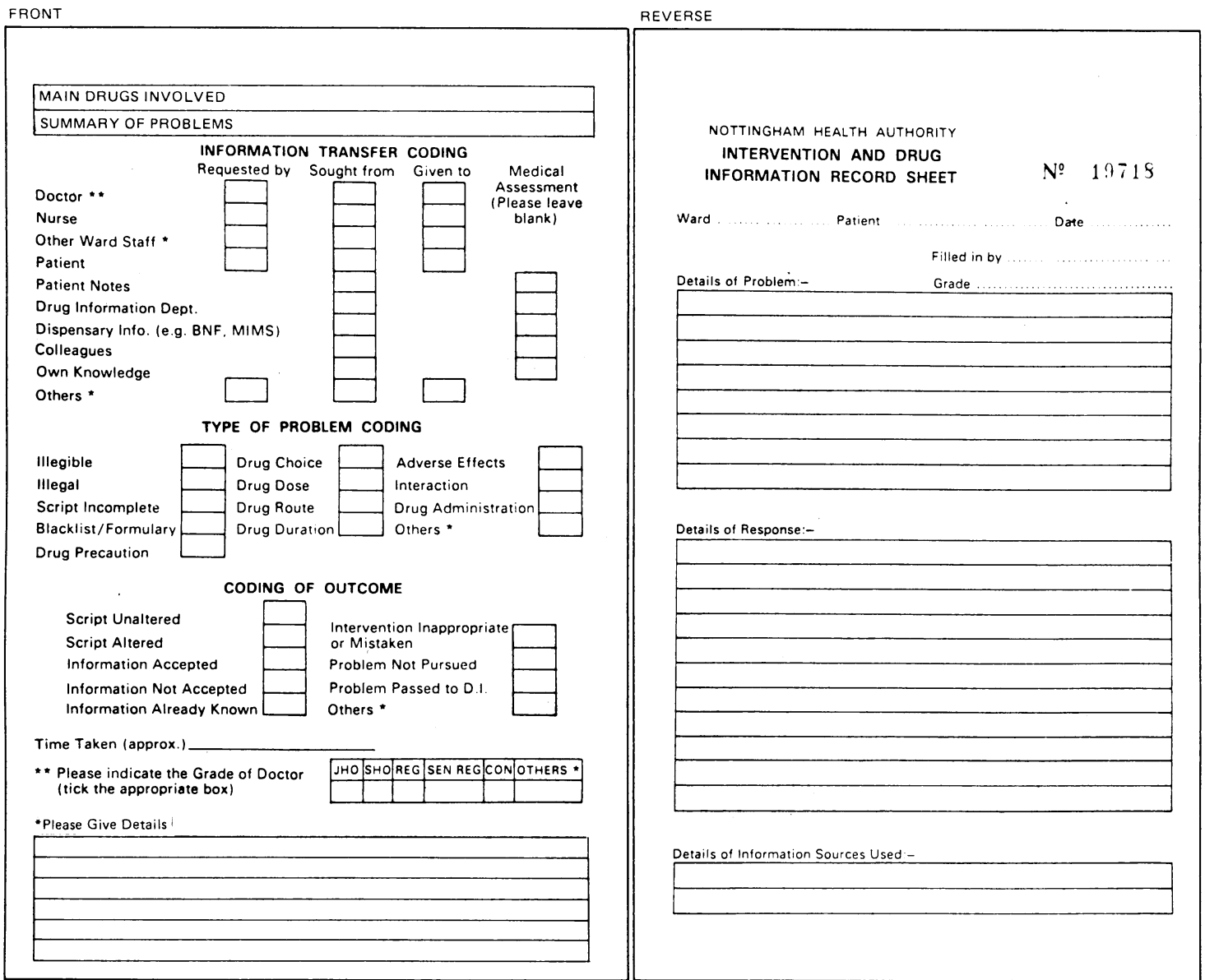

Standard (A5) form for recording all interventions by pharmacists. Details of problem, response, and information sources used entered on reverse of form

TABLE I-Categories of outcome resulting from prescribing error according to degree of harm

\begin{tabular}{lll}
\hline Category & \multicolumn{1}{c}{ Definition } & \multicolumn{1}{c}{ Example } \\
\hline Unnoticed & Impact on patient theoretical or undetectable & $\begin{array}{l}\text { Error resulting in impossible dosage (for example, sulphasalazine 800 mg twice daily) } \\
\text { Noticed }\end{array}$ \\
Detectable by patient but ultimate harm unlikely & $\begin{array}{l}\text { Antibiotic induced diarrhoea } \\
\text { Inadequate dose for relief of symptoms }\end{array}$ \\
Harmful & Patient experiences harm & $\left\{\begin{array}{l}\text { Inadequate dose for disease control } \\
\text { Prescription of sedative in liver failure }\end{array}\right.$ \\
Lethal & Patient dies because of error & $\left\{\begin{array}{l}\text { 10-Fold overdosage of intravenous hypotensive drug } \\
\text { Prescription of intravenous potassium bolus }\end{array}\right.$
\end{tabular}

evidence that doctors find these useful. ${ }^{5-7}$ These are essentially passive services. A third type of intervention, which entails monitoring prescriptions by pharmacists, who then seek amendment of those that are unclear, erroneous, inadequate, or inappropriate, may be described as reactive. With the development of clinical and ward pharmacy services this type of intervention is increasing, ${ }^{20-24}$ but there has been little assessment of its value. We therefore investigated pharmacy interventions made over one month in a district containing two teaching hospitals. We tried particularly to evaluate the extent to which prescribing errors would potentially harm patients' health and the extent to which their correction was medically beneficial.

\section{Methods}

Thirty five pharmacists in all hospitals in the Nottingham district recorded appreciable interventions during 28 days. The hospitals were: University and Nottingham City Hospitals (2530 available beds, mainly acute); Mapperley and Saxondale Hospitals (781 available mental illness beds); and the General, Sherwood, and Highbury Hospitals (633 available beds, mainly health care of the elderly). Pharmacists were instructed about the study at a series of special meetings and were told not to record minor inter- ventions, such as routine clarification of additional instructions (for example, "with food"), amendment of trade to generic names, and clarification of strength (unless confusing or dangerous). They were given written and verbal instructions with examples to explain the type of intervention that should be recorded. Interventions when information was requested by doctors or nurses (that is, a drug information service) were recorded but analysed separately. This paper concerns reactive interventions intended to improve a prescription with defects that might have a possible impact on the patient.

The pharmacists recorded relevant drug details, summarised and categorised the problem, and coded outcomes on a form (figure), and in addition recorded the total time taken to initiate and resolve the intervention and the grade of the prescribing doctor. The potential for medical harm was graded separately by a single doctor. The outcome(s) that the prescribing error could produce were identified and categorised according to the degree of harm that would have resulted if the outcome had actually occurred (table I). The prescribing error was then rated for potential medical impact with reference to the likelihood of the outcome occurring (table II).

In some instances the pharmacist's intervention was inappropriate, either because of a failure to appreciate more sophisticated prescribing behaviour by the 
doctor or because of defects in the pharmacist's knowledge. For example, intervening to prevent prescription of an opiate to a patient with carcinomatosis because the liver function tests showed abnormal results would represent an appreciable defect in the pharmacist's appreciation. Prescriptions prompting such interventions were recorded as having no potential medical impact. All interventions were graded for potential medical impact solely on the basis of information recorded on the forms. Any aspects of a case that were ambiguous or unclear were recorded as not evaluable. Two doctors independently rated the potential for medical harm for 103 interventions; their scores were correlated by Spearman's rank correlation coefficient.

\section{Results}

There was a significant correlation between the assessment of potential for medical harm by the two observers $(\mathrm{r}=0.83, \mathrm{p}<0.001)$.

\section{RATE OF INTERVENTION BY PHARMACISTS}

During a two week pilot phase conducted at University Hospital pharmacists intervened in 182 of 6170 prescriptions $(2 \cdot 9 \%)$. During the main study interventions were made at a similar rate, resulting in 769 interpretable interventions for the whole district. Table II shows the number of interventions made in terms of the pharmacist's characterisation of a problem and the medical evaluation of its potential impact on the patient.

Errors of dosage were the commonest reason for intervention by pharmacists. They comprised 280 prescriptions and included 32 of those judged to have a major potential for medical harm. Of these, nine concerned sedatives; eight analgesics; five cardiovascular drugs or diuretics; and five iron, vitamin, or mineral preparations. Table III shows the extent of these errors. Numerically, the largest errors concerned prescription of clonazepam $10 \mathrm{mg}$ twice daily (two) or $5 \mathrm{mg}$ twice daily (one), dihydrocodeine $1 \mathrm{~g}$ as required, Sytron iron preparation $10 \mathrm{ml}(v$ 10 drops) twice daily to a 1 month old baby, lorazepam $10 \mathrm{mg}$ twice daily, alfacalcidol $5 \mu \mathrm{g}$ thrice daily, tamoxifen $300 \mathrm{mg}$ daily, and atenolol $800 \mathrm{mg}$ daily. Errors which were numerically smaller but likely to be toxic because of a narrow therapeutic margin included five instances of inadvertent overdosage of nonsteroidal anti-inflammatory drugs (indomethacin $300 \mathrm{mg}$ daily, diclofenac $300 \mathrm{mg}$ daily, ketoprofen $50 \mathrm{mg}$ daily, naproxen $2 \mathrm{~g}$ daily, flurbiprofen $450 \mathrm{mg}$ daily). Prescription of a suboptimal dosage included that for amoxycillin $250 \mathrm{mg}$ daily for lobar pneumonia. Errors of dosage whose potential for medical harm was rated as "appreciable" included larger errors, excessive doses of toxic drugs such as gentamicin or chloramphenicol, or inadequate prescription of drugs for serious conditions. Many of the errors evaluated as having a minor potential for medical harm concerned the dosing interval of antibiotics. Twenty nine instances of prescription of drugs six hourly intended to be administered eight hourly ( 25 concerning amoxycillin) were counterbalanced by 20 instances when the opposite error was made. In consequence there was little cost implication. Individual drugs in which errors or confusion about dosage occurred commonly were chlormethiazole (six prescriptions), clotrimazole pessaries (five), erythromycin (six), iron preparations (eight), metronidazole (six), nifedipine (five), phenytoin (six), ranitidine (nine), salbutamol (six), and theophylline preparations (six).

TABLE III-Extent of errors of dosage with potential for serious harm, calculated as a percentage of intended optimum or maximum recommended dosage, as appropriate

\begin{tabular}{|c|c|c|c|c|c|c|}
\hline Dosage: & $20-50-$ & $67-$ & $100-150-$ & $200-5$ & $500-$ & $1000-3000$ \\
\hline No of interventions & 0 & 0 & 3 & 11 & 6 & 4 \\
\hline
\end{tabular}

Choice of drug was concerned in 129 interventions, most of which related to the appropriate choice of pharmaceutical preparation (enteric coated or not, slow release or not) and had little potential for medical harm. Use of opiates was inappropriate in six instances; some prescribers chose slow release morphine for initial pain relief, others prescribed diamorphine elixir for longer term use. Other errors included confusion of drug names (clonazepam $v$ clobazam, temazepam $v$ Temgesic, Trasicor $v$ Transiderm, chlormethiazole $v$ chlorhexidine, and dexamethasone $v$ dextromoramide).

Technical deficiencies accounted for 128 interventions; 76 concerned prescription of non-stock or nonformulary drugs, and in others the prescription was incomplete or illegible.

Duration of treatment accounted for 59 interventions; 48 of these concerned antibiotics. Table IV shows the number of excess days for which the drug had been administered at the time of the intervention. Twenty five courses of antibiotics were stopped on the appropriate last day of treatment as a result of the pharmacist's intervention. Interventions to terminate antibiotics had only a limited economic impact. The net daily cost of all the antibiotics concerned in these

TABLE II-Pharmacists' characterisation of intervention and medical evaluation of potential for harm ${ }^{\star}$ to patients. Figures are numbers of prescriptions (number concerning antibiotics)

\begin{tabular}{|c|c|c|c|c|c|c|c|c|c|c|c|}
\hline \multirow[b]{2}{*}{$\begin{array}{l}\text { Potential for } \\
\text { medical harm }\end{array}$} & \multirow[b]{2}{*}{ Definition } & \multirow[b]{2}{*}{$\begin{array}{c}\text { Example } \\
\text { (dose errors) }\end{array}$} & \multicolumn{9}{|c|}{ Characterisation of intervention } \\
\hline & & & $\begin{array}{l}\text { Prescription } \\
\text { inadequate }\end{array}$ & $\begin{array}{l}\text { Inappropriate } \\
\text { choice of } \\
\text { drug or } \\
\text { route }\end{array}$ & $\begin{array}{l}\text { Wrong } \\
\text { dose }\end{array}$ & $\begin{array}{c}\text { Dose or } \\
\text { strength } \\
\text { not known } \\
\text { or } \\
\text { not stated }\end{array}$ & $\begin{array}{l}\text { Wrong } \\
\text { duration }\end{array}$ & $\begin{array}{l}\text { Problem with } \\
\text { prescribing } \\
\text { precautions, } \\
\text { adverse effects, } \\
\text { or interactions }\end{array}$ & $\begin{array}{c}\text { Errors } \\
\text { in } \\
\text { administration }\end{array}$ & Other & Total \\
\hline None & & $\begin{array}{l}\text { Ibuprofen } 300 \mu \mathrm{g} \text { four } \\
\text { times daily }\end{array}$ & $93(8)$ & $40(5)$ & $79(20)$ & 0 & $17(13)$ & $15(6)$ & $15(1)$ & $10(1)$ & $269 \cdot(54)$ \\
\hline Minor & $\begin{array}{l}\text { Any chance of unnoticed } \\
\text { effect } \\
<5 \% \text { Chance of noticed } \\
\text { effect }\end{array}$ & $\begin{array}{l}\text { Amoxycillin } 250 \mu \mathrm{g} \text { four } \\
\text { times daily }\end{array}$ & $21(6)$ & $66(33)$ & $104(60)$ & $39(0)$ & $16(10)$ & $7(2)$ & $5(2)$ & $7(0)$ & $265(113)$ \\
\hline Appreciable & $\begin{array}{l}>5 \% \text { Chance of noticed } \\
\text { effect }\end{array}$ & $\begin{array}{l}\text { Gentamicin } 1.5 \text { times } \\
\text { correct dose }\end{array}$ & $11(0)$ & $19(2)$ & $65(20)$ & $11(1)$ & $25(25)$ & $27(2)$ & $11(1)$ & $6(2)$ & $175(53)$ \\
\hline Major & $\begin{array}{l}>20 \% \text { Chance of noticed } \\
\text { effect } \\
>5 \% \text { Chance of harmful } \\
\text { effect } \\
\text { Any chance of lethal effect }\end{array}$ & $\begin{array}{l}\text { Clonazepam } 10 \mathrm{mg} \text { twice } \\
\text { dailyt }\end{array}$ & $3(0)$ & $4(0)$ & $32 \quad(2)$ & 0 & $1(0)$ & $9(1)$ & $8(0)$ & $3(0)$ & 60 \\
\hline
\end{tabular}

\begin{tabular}{|c|c|c|c|c|c|c|c|c|c|}
\hline Total & $128(14)$ & $129(40)$ & $280(102)$ & $50(1)$ & $59(48)$ & $58(11)$ & $39(4)$ & $26(3)$ & $769(223)$ \\
\hline
\end{tabular}


interventions was $£ 7.42$ whereas the total financial wastage for the excess days that antibiotics were actually received was $£ 24.16$ for all hospitals in the entire 28 day period (according to current Nottingham hospital contract prices).

TABLE IV-Errors in duration of prescription and administration of antibiotics, according to number of days in excess of intended duration or of that recommended by the "British National Formulary" at time of intervention

$\begin{array}{lllllllllllll}\text { No of days: } & -1 & 0 & 1 & 2 & 3 & 4 & 5 & 6 & 7 & 8 & 9 & 10\end{array}$

$\begin{array}{lllllllllllll}\text { No of interventions } & 1 & 25 & 7 & 1 & 2 & 4 & 5 & 1 & 3 & 0 & 0 & 3\end{array}$

Prescribing precautions, adverse effects, and interactions - Fifty eight interventions drew attention to prescribing precautions (for example, gentamicin concentrations, omission of folinic acid rescue), adverse drug effects (for example, diuretic induced hypokalaemia or antibiotic induced diarrhoea), and drug interactions. As table $\mathrm{V}$ shows, most of the 14 drug interactions identified were fundamental and clinically important; six concerned warfarin. In

TABLE V-Drug interactions identified by pharmacists

\begin{tabular}{ll}
\hline Type of interaction & \multicolumn{1}{c}{ Drugs concerned } \\
\hline Pharmacokinetic & Aminophylline, erythromycin (two) \\
& Tetracycline, Gaviscon \\
& Warfarin, amiodarone \\
& Warfarin, phenytoin \\
& Warfarin, piroxicam \\
& Warfarin, stanozolol \\
& Dextromoramide, buprenorphine \\
& Loperamide, lactulose, and co-danthramer \\
Metoclopramide, propantheline bromide & Potassium, enalapril $\dagger$ \\
Pharmacodynamic & Warfarin, vitamin K \\
& Warfarin, aspirin \\
& Azlocillin, gentamicin
\end{tabular}

* Partial agonist activity of buprenorphine makes it unsuitable for coprescription with other opiates.

†Patient hyperkalaemic.

addition, there were seven instances when large doses of paracetamol or aspirin were coprescribed as plain and compound (co-proxamol and Benoral) or for regular use and as required, or both. One patient was prescribed co-proxamol two tablets four times daily, paracetamol $1 \mathrm{~g}$ four times daily, co-proxamol two tablets as required, and paracetamol $1 \mathrm{~g}$ as required.

Errors in administration arose in 39 instances, including use of an inappropriate preparation for parenteral administration and one incident when a contaminated syringe pump was identified. Six instances concerned administration of drugs (silver sulphadiazine (Flamazine), papaveretum, and tetracosactrin (Synacthen)) or infusions (dopamine, etomidate, and insulin) which had not been prescribed.

\section{ACCEPTANCE OF PHARMACIST'S RECOMMENDATION}

In 639 cases $(83 \%)$ the pharmacist's intervention was accepted, resulting in an alteration of the prescription in $575(75 \%)$; in 92 the prescription was unaltered or the information was not accepted; in eight the information was already known; and in five the pharmacist considered that the intervention was inappropriate; a further 25 interventions were considered inappropriate by the medical assessor.

\section{OUTCOME}

Overall, there was an appreciable improvement in the quality of the prescription in 246 cases or a minor improvement in 231 . In 185 cases the intervention had no discernible effect, and in 107 its influence was unclear. Most interventions $(427 / 646,66 \%$ ) had no effect on costs, 130 resulted in a saving of less than $50 \mathrm{p}$, and in 39 there was a larger saving. Some interventions increased drug costs (by less than $50 \mathrm{p}$ in 46 cases and by more in four).

\section{TIME ASSOCIATED WITH INTERVENTION}

A record of the time taken to make and to resolve the intervention was available for 730 of the 769 interventions and comprised a total of 96.7 pharmacist hours, representing an average of 41 minutes per pharmacist per week. The average time to resolve each problem was 7.9 (SE 0.8) minutes. Those problems involving the correct choice of drug and its administration (choice of drug, dose, route, duration, consideration of adverse effects, interactions, and administration) took significantly longer $(9 \cdot 1$ $(1 \cdot 8)$ minutes) than more bureaucratic interventions (illegible, illegal, or incomplete prescriptions and prescribing of non-formulary items), which took 6.4 $(4 \cdot 6)$ minutes $(\mathrm{p}<0 \cdot 05)$.

\section{Discussion}

Much of the scrutiny of medical behaviour and prescribing that is currently performed is based on economic appraisal. The reasons for this include ease of measuring and the current political emphasis on cost in the NHS. Previous studies in the United States have shown that pharmacists can reduce costs ${ }^{1819}$ and can save money for patients (at the fairly modest rate of $\$ 9.13$ per pharmacist hour invested)..$^{25}$

In some studies there was a concurrent improvement in general prescribing standards, but we are aware of only two small studies that have specifically attempted to measure the potential medical impact of the errors that are corrected by pharmacy interventions. Keys et al reported a total of 48 interventions and concluded that there was likely to have been a beneficial impact on patients. ${ }^{20}$ In another study Folli and colleagues recorded the interventions made during six months in two paediatric units in California. ${ }^{24}$ Although the pattern observed reflected paediatric practice, many of their results mirror ours. Errors of dosage were the most common, and errors concerning antibiotics, theophylline, analgesics, and anticonvulsants were frequent. Interestingly, the principles by which potential medical impact was evaluated were similar to ours, although the two studies were initiated and conducted independently. Our scale differs in including an estimate of the likelihood of an adverse event occurring as well as its severity as it is usually a potential for harm that is averted by reactive pharmacy intervention. Although assessment of the potential for medical harm entails a judgment, it was structured according to the criteria in tables I and II, and the scores ascribed independently by two medical assessors correlated well.

Some limitations remain in the approach we have adopted. Firstly, any intervention entails judgment by the pharmacist, and the recording of an incident is inevitably one sided. However, most interventions seemed reasonable because $83 \%$ of items of advice were accepted and suggestions were adopted. In those cases when agreement was not reached the medical assessor allowed for bias in the report and did not grade interventions when there was possible ambiguity. Secondly, the survey concentrated only on faults in prescribing. It had no power to record or measure the extent of prescribing excellence or its rate compared with poor prescribing. A third and related problem is that the survey did not measure the number of errors missed by the pharmacist when an intervention should have been made. Within these constraints certain conclusions may be drawn. The proportion of interventions that might have a serious impact on a patient is fairly small. In the context of large numbers of hospital prescriptions, however, this represents a 
continuing potential for hazard and emphasises the need for an effective backup safety mechanism. Our study shows that this may be achieved with only a modest investment of pharmacists' time.

In strictly financial terms, however, reactive pharmacy intervention costs more than it saves. The costs of overprolonged antibiotic prescribing were not great. Precise assessment of net savings for all drugs is not possible but is unlikely to have exceeded $£ 250$. The costs of pharmacists' time were higher-the overall salary costs based on current middle grade pharmacists' salaries (with $20 \%$ allowance for national insurance, superannuation, etc) amount to $£ 877$ per month. The purpose of the service, however, was not to save money but to improve medical care, and a strict financial assessment is as inappropriate here as it is in many of the other areas within the NHS where it is currently being applied. Salary expenditure of $£ 14.17$ per case in which a serious potential for medical harm was averted or $\$ 3.73$ per case in which appreciable or serious potential for medical harm was averted seems both reasonably cost effective and probably cost saving if potential losses from litigation are considered.

Perhaps the greatest value of the study was to identify specific areas where prescribing was poor. For example, errors of dosage for chlormethiazole probably reflect the rather unusual tablet strength (192 mg), and similarly, those with metronidazole may have arisen because of differences in unit dose for intravenous $(500 \mathrm{mg})$ and oral $(400 \mathrm{mg})$ preparations. Most of the drugs in which common errors of dosage occurred are widely used. In some-for example, phenytoin and theophyllines, in which there is a narrow therapeutic margin - there was an appreciable risk to the patient. One unforeseen finding was a confusion between clonazepam ( $500 \mu \mathrm{g}$ or $2 \mathrm{mg}$ tablets) and clobazam (10 mg capsules), in which dosage errors could cause serious harm. Another common problem was inadvertent overprescription of paracetamol by concurrent use of paracetamol BP, co-proxamol, and benorylate. In this sense the survey has been valuable in identifying suspected and unsuspected prescribing problems. It was clear that a fairly limited number of errors are made repeatedly. They can therefore be easily avoided by targeted educational measures which, in our hospitals, have taken the form of an informative monthly prescribers' newsletter.
I Hatoum HT, Catizone C, Hutchinson RA, Purohit A. An eleven-year review of the pharmacy literature: documentation of the value and acceptance of clinical pharmacv. Drug Intell Clin Pharm 1986;20:33-42.

2 Klotz R. Steffens S. Improved pharmacy services through pharmacis participation in medical rounds. Am $\mathcal{F}$ Hosp Pharm 1976;33:349-51.

3 Gibson P, Freeborn SF. Are pharmacists effective on clinical rounds? Pharmaceutical fournal 1985;234:201-2.

4 Trewin VF, Town R. Pharmacist effectiveness at case conferences. British Journal of Pharmaceutical Practice 1986;8:298-304.

5 Merritt GJ, Garnett WR, Eckel FM. Anal is of a hospital-based drug information center. Am $\mathcal{Y}$ Hosp Pharm 1977;34:42-6.

6 Hayman JN, Brown TR, Smith MC, Liao W. Physician use and evaluation of a hospital-based drug information center. Am f Hosp Pharm 1978;35: $1238-40$.

7 Schweigert BF, Oppenheimer PR, Smith WE. Hospital pharmacists as a source of drug information for physicians and nurses. Am f Hosp Pharm 1982;39:74-7.

8 Elenbaas RM, Payne VW, Bautman JL. Influence of clinical pharmacist consultations on the use of drug blood level tests. A $m$ f Hosp Pharm 1980;37:61-4.

9 Schloemer JH, Zagozen JJ. Cost analysis of an aminoglycoside pharmacokinetic dosing program. Am f Hosp Pharm 1984;41:2347-51.

10 Noel MW, Paxinos J. Cephalosporins: use review and cost analysis. $A m \mathcal{f} H o s f$ Pharm 1978;35:933-5.

11 Angell Sohn C, Wolter HA, McSweeney GW. Effectiveness of a cephalosporin education program - a pharmacy education program. Drug Intell Clin Pharmacol 1980;14:272-7.

12 Seligman SJ. Reduction in antibiotic costs by restricting use of an ora cephalosporin. Am J Med 1981;71:941-4.

13 Norris SM. Evaluation of gentamicin prescribing after drug-use review. Am f Hosp Pharm 1982;39:1529-30.

14 Avorn J, Soumerai SB. Improving drug-therapy decisions through educational outreach. A randomised controlled trial of academically based "detailing." NEngl F Med 1983;308:1457-63.

15 Mutchie KD, Smith KA, MacKay MW, Marsh C, Juluson D. Pharmacis monitoring of parenteral nutrition: clinical and cost effectiveness. Am 7 Hosp Pharm 1979;36:785-7.

16 Alexander MR, Alexander B, Mustion AL, Spector R, Wright CB Therapeutic use of albumin: 2. FAMA 1982;247:831-3.

17 Berbatis CG, Maher MJ, Plumridge RJ, Stoelwinder JU, Zubrick SR. Impac of a drug bulletin on prescribing oral analgesics in a teaching hospital. Am f Hosp Pharm 1982;39:98-100.

18 Rav W'A, Blazer DG, Shaffner W, Federspeil CF, Fink R. Reducing long-term diazepam prescribing in office practice. A controlled trial of educational visits. JAMA 1986;256:2536-9.

19 Evans EC, Haynes B, Birkett NJ, et al. Does a mailed continuing education program improve physician performance? JAMA 1986;255:501-7.

20 Keys PW, South JC, Duffy MG. Quality of care evaluation applied to assessment of clinical pharmacy services. Am $\mathcal{F}$ Hosp Pharm 1975;32 $897-902$.

21 Shane R, Miller J, Cohen J. Educating hospital decision-makers abou pharmacists' interventions. Am J Hosp Pharm 1985;42:1928, 1934

22 Comer JB. Documenting pharmacists' interventions. Am f Hosp Pharm 1985;42:625-6.

23 Ross AJ. Evaluating the benefits of a clinical pharmacy service. Pharmaceutical Joumal 1985:234:683-5.

24 Folli HL, Poole RL, Benitz WE, Russo JC. Medication error prevention b clinical pharmacists in two children's hospitals. Pediatrics 1987;79:718-22.

25 Ryan PB, Johnson CA, Rapp RP. Economic justification of pharmacis involvement in patient medication consultation. Am $\mathcal{f}$ Hosp Pharm 1975;32:389-92.

(Accepted 5 fanuary 1990)

\section{ANY QUESTIONS}

What modification should be made in the insulin treatment of an elderly man with longstanding diabetes who develops gastroenteritis?

Insulin treatment must be continued in this patient. Frequent blood glucose monitoring is essential to identify hypoglycaemia or hyperglycaemia and urine analysis should be done to detect ketonuria and so indicate any need for additional insulin - for example, ketones "small," 2 extra units; ketones "moderate," 4 extra units; ketones "large," 6 units of short acting insulin. The patient should be encouraged to take his exchanges in a lighter form spread throughout the day: suitable substitutes for $10 \mathrm{~g}$ of carbohydrate are a glass of milk, a small scoop of ice cream, a natural yoghurt (one pot), or natural, unsweetened fruit juice (one wine glass). A liberal intake of sugar free fluids should be encouraged.

Symptomatic treatment should be given for gastroenteritis. If there is clinical evidence of dehydration or acidosis immediate hospital admission should be arranged to allow correction of metabolic instability. Diabetic ketoacidosis may have a high mortality in the elderly, and if domestic back up is poor early rather than late admission should be arranged. A short admission may well prevent decompensation.

Prevention is the best approach, and two excellent leaflets, Coping When You Are Ill and on Insulin and Coping When You Are Ill and on Tablets or Die
Alone, are available from the British Diabetic Association, 10 Queen Anne Street, London W1M 0BD. Such leaflets should be given to all patients or relatives at diagnosis. -D W M PEARSON, consultant physician, Aberdeen

Is there any limit of the maintenance dose of sulphasalazine in patients with ulcerative colitis? What are the risks of long term toxicity for a patient who has been taking 8-9 $\mathrm{g}$ a day for four years to keep her symptoms suppressed?

There is no firm evidence on which to base answers to either of these questions. Khan et al, however, in a controlled trial comparing 1,2 , and $4 \mathrm{~g}$ of sulphasalazine as maintenance treatment over six months, showed that $4 \mathrm{~g}$ gave a better therapeutic response than $2 \mathrm{~g}$ daily. ${ }^{1}$ The difference was not great and the incidence of side effects with the higher dose was considerably increased compared with that seen with the $2 \mathrm{~g}$ dose. Therefore, although higher doses can be used, the incidence of side effects may be high and the therapeutic gain seems to fall exponentially as the dose is increased. So far as is known, there is no long term toxicity for a patient taking $8-9 \mathrm{~g}$ daily, but this has not been systematically studied. $-\mathrm{D} P$ JEWELL, consultant physician, Oxford

1 Khan AKA. Howes DT, Piris J, Truelove SC. Optimum dose of sulphasalazine for maintenance treatment in ulcerative colitis. Gut 1980;21:232-40. 